\title{
Revisiting (Some of) the Lasting Impacts of the Liberty Ships via a Metallurgical Analysis of Rivets from the SS "John W. Brown"
}

\author{
M.D. HARRIS, ${ }^{1}$ W.J. GROGG,${ }^{1}$ A. AKOMA,${ }^{1}$ B.J. HAYES,${ }^{1}$ \\ R.F. REIDY, ${ }^{1}$ E.F. IMHOFF ${ }^{2}$ and P.C. COLLINS ${ }^{3,4}$ \\ 1.-Department of Materials Science and Engineering, University of North Texas, Denton, \\ TX 76205, USA. 2.-Baltimore Sun, Baltimore, MD, USA. 3.-Department of Materials Science \\ and Engineering, Iowa State University, Ames, IA 50011, USA. 4.-e-mail: pcollins@iastate.edu
}

During World War II, 2710 Liberty ships were built in the United States across 18 ship yards. The rate of production of these ships was at a scale not previously witnessed, reflecting a strategic marshaling of national assets critical to the war effort. For the metallurgist, metallurgical engineer, or materials scientist, these ships also struck commanding images regarding their catastrophic failures. The study of these failures led to increased understanding of brittle fracture, fracture mechanics, and ductile-to-brittle transition temperatures. The post-mortem studies of Liberty ships highlighted the importance of composition and microstructure in controlling the properties of steel in fracturecritical applications. This study examines a rivet from the SS "John W. Brown", which was assembled in Baltimore, Maryland, and launched in September 1942, The "John W. Brown" was restored between 1988 and 1991. Classical metallurgical analysis of a rivet from the original 1942 vessel is compared with modern rivets used during its restoration. The rivets provide an analogue to the plate material used in these ships. A comparison of these materials is presented along with a discussion of the importance of composition-microstructureproperty relationships that concomitantly evolved.

\section{INTRODUCTION}

A metallurgical study of material obtained from the "John W. Brown" (see Fig. 1a and b), a U.S. Liberty ship, provides an opportunity to reflect on how these ships came to catalyze significant national, social, and technical advances. The incredibly rich story of these vessels is far more than the common historical footnote that these were 'the ships that broke'. While the technical work presented in this article is motivated by a metallurgical analysis of two rivets, it is important to understand the other significant advances that were made as a result of Liberty ship construction and failures. Therefore, a historical retrospective is provided prior to the metallurgical analysis, a prologue on the construction and sailing of the Liberty ships. In addition to the historical context, the

E. F. Imhoff is now retired from Baltimore Sun, Baltimore, MD, USA. introduction includes descriptions of the previously unknown phenomenon associated with notch sensitivity, and the subsequent rapid efforts to understand it, codifying it in ductile-to-brittle transition temperatures (DBTT) and nil ductility transition temperatures (NDTT), and recollections of the importance that notable individuals played in the scientific process.

\section{Prologue: The Liberty Ships and the "John W. Brown"}

In the twenty-first century, it is hard to imagine the spectacularly complex and massive shipbuilding and seamanship undertaken by the United States during World War II. More than 6000 ships were built from before 1941 to 1945, including 2710 emergency Liberty cargo ships. The peak point of Liberty production was early 1943. Thousands of workers flocked from small towns, big cities, and in between to assemble every 441-foot, 58-foot-wide ship using $\sim 250,000$ individual parts. 

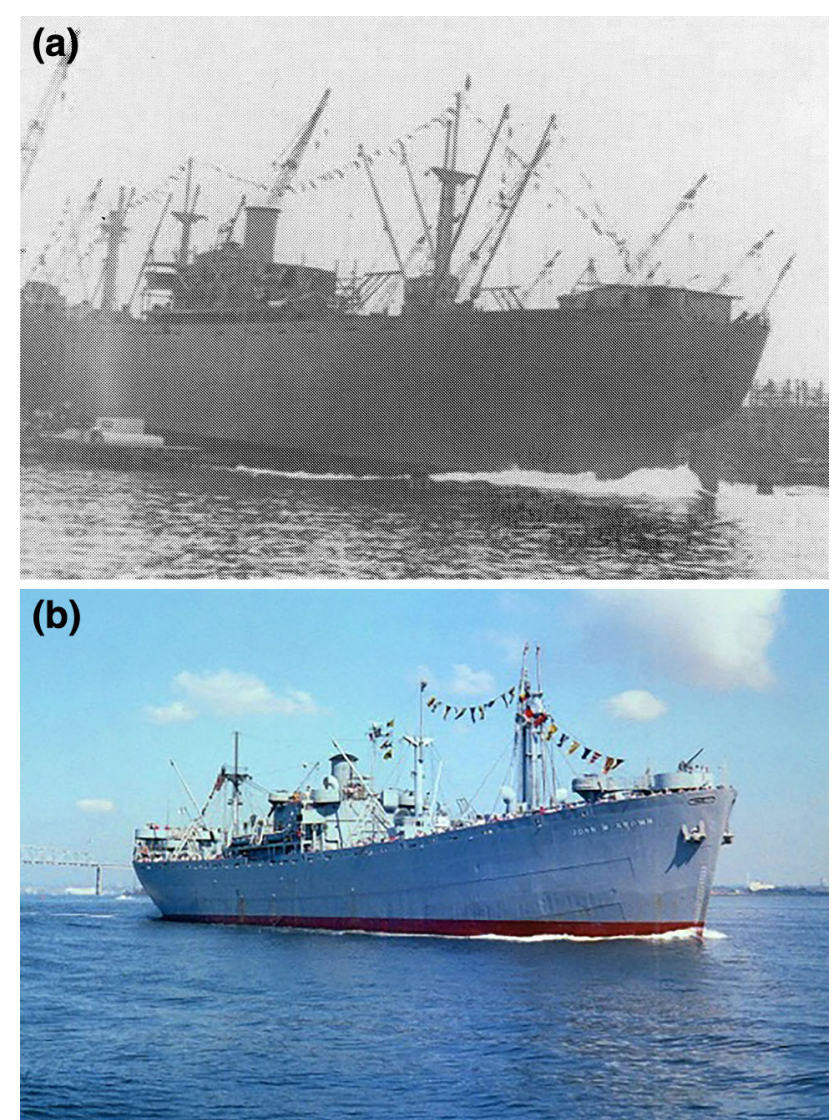

Fig. 1. The SS "John W. Brown" (a) upon launching ${ }^{2}$ and (b) underway in the Chesapeake Bay on a Living History cruise (E.F. Imhoff).

The single shipyard assembling the most ships was Bethlehem-Fairfield in Baltimore with 384 Liberty vessels. Bethlehem-Fairfield was the only yard of the 18 where all shell plate seams, those running fore and aft between plates, were riveted. Some shipyards built Liberty ships that were all welded and other yards used both rivets and welding. The vertical joints called butts were welded in all Liberty ships. ${ }^{1}$

Following the first voyage in 1942, from 1943 to 1945, the "John W. Brown" sailed seven times with war goods and troops mostly to the Mediterranean. Following World War II, the "John W. Brown" became a non-sailing maritime high school for seagoing young people in New York City from 1946 to 1982 . From 1983 to 1988 , the "John W. Brown" was anchored in the Defense Fleet in the James River. The "John W. Brown" still sails today from Baltimore as a historic Living History ship after rescue by Maryland volunteers in 1988 from the James River National Defense Reserve Fleet in Virginia.

The Liberty ships were part of the American merchant marine serving the fighting troops (some became military ships). They carried the food, weapons, ammunition, medical supplies, and fighting gear; everything needed to wage war. Steamship companies operated them, civilians served on them and U.S. Navy Armed Guardsmen manned their guns. Not technically warships, they sailed through warzones, in convoys, came under attack, and saw action.

U-boats were sinking many Allied ships in the early war years, but by February 1943, Liberty tonnage had increased and finally passed the tonnage of ships sunk by the submarines. More and more U-boats were being sunk and more Liberties were built as the war continued.

All steaming Liberty ships are gone from the high seas today save for the "John W. Brown" in Baltimore and the S.S. "Jeremiah O'Brien" in San Francisco. They sail with passengers on Living History day cruises. The "Hellas Liberty", once the SS "Arthur M. Huddell", is a stationary historical Liberty in Greece. The "John W. Brown" sails with the original Huddell rudder, one of many old parts the "John W. Brown" acquired from discarded Liberty ships with U.S. Maritime Commission approval.

For those interested, some rich sources of information on the Liberty ships are given in Refs. 1-6.

\section{The Historical Story: Technology and People}

Importantly, the selection of the original design for the Liberty ship was based upon a pressing national need to rapidly establish an emergency cargo fleet of vessels that would be fast, reliable, and cheap to build. In addition to moving significant numbers of troops and supplies, a large number of vessels were needed to counter the maritime losses being faced by the Allied troops. To achieve these objectives, an outdated but very reliable design (the Ocean class) whose origins traced back more than 60 years (to the British Sunderland Tramp design, 1879 ) powered by 140 -ton vertical triple expansion steam engines (also obsolete) was adopted. These decisions were made because it enabled more companies to contribute to the industrial effort. Some notable changes to the obsolete designs were made. They were modified to increase the displacement (i.e., cargo weight) to over 10,000 tons, conform to assembly-line type practices, use oil-fired (instead of coal) boilers, and, importantly, replacing many of the rivets with welds. The resulting design was officially known as the EC2-S-C1 for: EC = Emergency Cargo; 2 = length class (between 400 and 450 feet in length at the waterline); $\mathrm{S}=$ Steam; and, notably for getting the first design into the water and indicating the maturity of the baseline design, $\mathrm{C} 1=$ design 1 . However, where the Liberty ships were a very functional, reliable, and cheap vessel to produce, they were also of an anticipated finite lifetime of five years, and were perceived as unattractive. Indeed, they were called 'dreadful looking' by U.S. President Franklin D. Roosevelt and an 'ugly duckling' by Time magazine. ${ }^{7,8}$ 


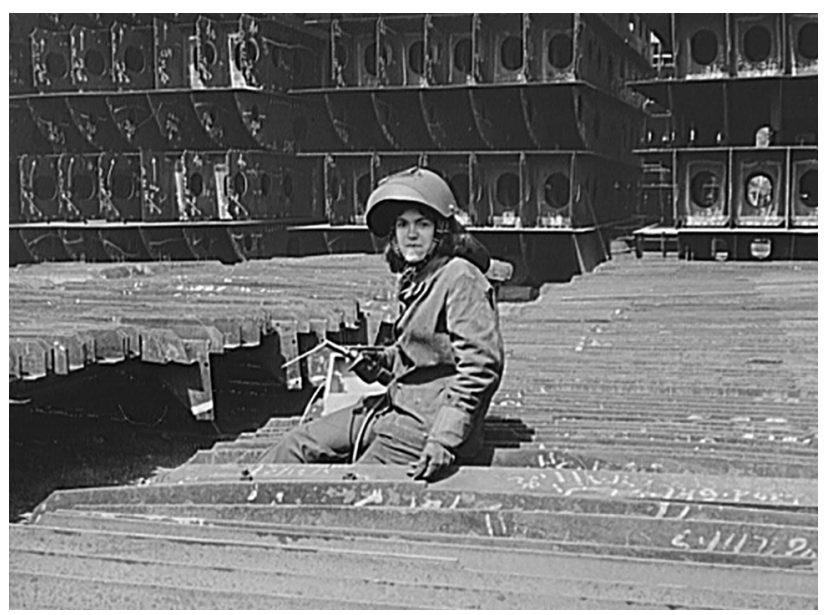

Fig. 2. An unidentified "Wendy the Welder" at the Bethlehem-Fairfield Shipyard, likely butt welding the vertical joints from Ref. 2. Original photo: Library of Congress (Arthur S. Siegel, photographer, U.S. Farm Security Administration).

The Liberty ships are also strongly associated with the need to increase participation of women in the workforce. While women were increasingly being employed in various other industries critical to the war effort, it is notable that the National Historic Park dedicated to the role of women during World War II (Rosie the Riveter/World War II Home Front National Historical Park) is in the shipyards of Richmond, California; home to Henry J. Kaiser's Richmond Liberty shipyards. It is also in close proximity, and commemorates the activities of, the Richmond Ford Motor Company Assembly Plant, which was one of only three tank depots in the United States. ${ }^{9}$ In addition to the well-known 'Rosie the Riveter', the role of women in the Liberty shipyards (see, for example, Fig. 2) also included 'Wendy the Welder' based on Janet Doyle, a worker at the same Richmond shipyards. ${ }^{10}$

In modern metallurgical history, these aforementioned facts may not be known or appreciated, given the other importance that these ships played in the understanding of the performance of materials. The metallurgists are more likely to associate these ships with their catastrophic failures. Three of the 2710 Liberty ships built literally 'broke in half', very similar to the T2 tankers, including the SS "Schenectady" of photographic fame, as well as the "Pendleton" and "Fort Mercer", each which split in two on the same day off Cape Cod (see Fig. $3^{11}$ ). The Liberty ship failures lead to the loss of $\sim 10$ lives (all 10 in only 1 event). In addition, there were another 1500 cases of brittle fractures in ship hulls and decks during World War II. Some suspicion fell upon the untrained welders and the new welding techniques that were being employed to keep pace with the demands of the National war effort. The welding of these ships was not the key factor to any performance issues, as we now know. Welding played a role only in three ways. Firstly, welding

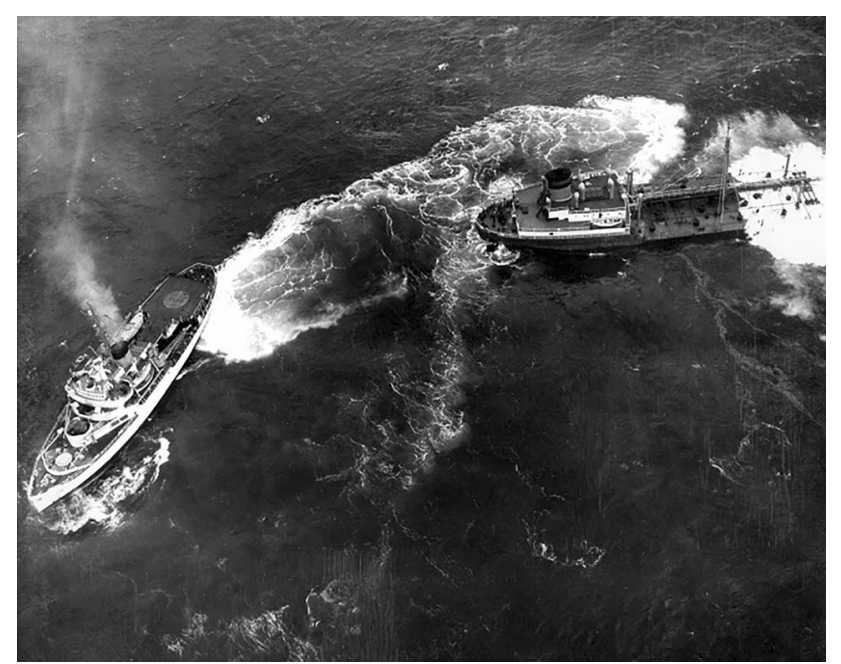

Fig. 3. The T2 tanker "Fort Mercer" off of Cape Cod on February 19, 1952 being circled by the U.S. Coast Guard icebreaker, "Eastwind". ${ }^{11}$

created a more monolithic piece that allowed cracks which, once initiated, could self-propagate carrying a sharp notch at the crack tip. The monolithic pieces also provided greater constraints that would lead to larger stresses at concentrators. Secondly, welding was typically performed in regions which already contained a 'geometric discontinuity' (i.e., geometric notch), placing the weld in intimate contact with the initiating notch. Thirdly, occasionally, welds would contain a defect that served as a stress concentrator. It was most common that the defects would arise from the welds associated with the bilge keels, where a bulb bar was used to form the keel. The hull plating would be welded to the bulb (a challenging weld to be sure), and one where welding defects (e.g., incomplete welding) was more prone to occur. ${ }^{2}$ One could argue that welding played one final role, in that it reduced cost and allowed for a significant population of steel in structural applications. The proliferation of these structures, and the corresponding large number of failures, allowed for the DBTT to be identified as a statistically meaningful problem to be addressed. Indeed, prior to these ships, only one brittle fracture (the Hasselt Road Bridge, Belgium, 1938) had led to a notable failure. Thus, welding and the welders (e.g., Wendy the Welder) received very unfair and unwarranted suspicion. In reality, and as was understood later, it was the grades of steel used (both composition and microstructure) that contributed predominately to these brittle failures.

Obviously, there was a problem. The Liberty ships (and others, including the RMS "Titanic"12,13) were failing in a catastrophic and as-yet unknown manner. When the Liberty ships were designed and built, there was not an awareness of the DBTT or of the NDTT. Only in 1943 did a correlation between temperature and notch sensitivity begin to be 
understood, after the construction of Liberty ships was well underway. In fact, according to a careful review ${ }^{14}$ by Williams and Ellinger for the Ship Structure Committee convened by the U.S. Secretary of the Treasury and chaired by Ellis Reed-Hill, the "specifications for steel for hull construction in effect at the time of purchase" were based on the tensile strength, yield point, and an unusual measure of elongation. Most of the plates that failed with a brittle fracture would have passed the standards of the day, location-to-location variability for the rimmed steel of the day notwithstanding. The shipping community needed to understand, and solve, the problem. Two notable efforts stand out to address the nature of these brittle fractures.

Interestingly, the reader might recognize the last name Reed-Hill. Ellis Reed-Hill was a Rear Admiral, United States Coast Guard, and Chairman of the Ship Structure Committee which reported the work of Morgan L. Williams and George A. Ellinger of the National Bureau of Standards in their report "Fractured Steel Plates Removed from Welded Ships", covering work from 1942 to 1948 . He was later awarded the Legion of Merit. His son, Robert E. Reed Hill, also served in the U.S. Coast Guard. Upon retiring, he then went to the University of Florida, where he was very active in research in physical metallurgy, including writing the first edition of Physical Metallurgy Principles, a seminal physical metallurgy book for many students. ${ }^{15-18}$

\section{Williams and Ellinger (the U.S. Effort)}

The first is the aforementioned report by Williams and Ellinger, ${ }^{14}$ which details the investigations of not only the Liberty ships but of other vessels of the day. The report details events during the winter of 1942-1943, when two cargo vessels located in the North Atlantic, one tank vessel off the coast of New York, and another tank vessel (the SS "Schenectady", and similar tankers (shown in Fig. 3)) at a dock in Oregon snapped completely in two following their sea trials. At all three locations, water temperatures averaged from $\sim 0^{\circ} \mathrm{C}$ to $\sim 7^{\circ} \mathrm{C}$, with air temperatures ranging from $\sim-2^{\circ} \mathrm{C}$ to $\sim 5^{\circ} \mathrm{C}$. Over the next decade, many other vessels experienced less catastrophic material failure. By 1947, approximately 60 U.S. ships ( $\sim 50 \%$ being Liberty ships) required structural components (e.g., plates) replacement due to fractures that occurred when exposed to operating temperatures below $\sim 5^{\circ} \mathrm{C}$. In an effort to better understand the problem, the Naval Department Bureau of Ships, and then the National Bureau of Standards (NBS), received 83 samples from 48 of these 60 ships to test for material properties, including the DBTT. Some important clues were found using the v-notch Charpy test on the residual material. For example, in general, the cracks initiated in the plate material exhibited the lowest energy absorbed during testing (i.e., brittle), propagated through plates exhibiting intermediate energy absorption, and terminated in plates exhibiting the highest energy absorption (i.e., least notch-sensitive). Once the data was plotted, and the threshold of $20.3 \mathrm{~J}$ ( $15 \mathrm{ft}-1 \mathrm{bs}$ in the original units) was determined, only 8 of the 83 samples tested had DBTTs at or below $7^{\circ} \mathrm{C}$, meaning that $90 \%$ of the specimens would have exhibited a brittle failure (and with a lower impact energy) at or below this temperature. Thus, any weak points within the ships could easily become the initiating points for brittle fractures under much more temperate water and air temperatures than expected, because service temperatures were below the nominal DBTT. To exacerbate this problem, welded structures allowed the cracks to propagate through multiple plates. DBTTs for plates tested from the Liberty Ships ranged from $-4.4^{\circ} \mathrm{C}$ to $66^{\circ} \mathrm{C}$, while averaging around $24.8^{\circ} \mathrm{C} .^{14}$

\section{Constance Tipper (the U.K. Effort)}

The other notable effort to understand what was occurring in these materials was conducted by the British Admiralty Ship Welding Committee, which engaged Constance Tipper (see feature article in this issue of $\mathrm{JOM}^{19}$ ) to lead the metallurgical investigation. Tipper was a trail-blazing woman who was the first woman to take the Natural Sciences Tripos, in 1915, at the University of Cambridge. She then launched a distinguished career as a metallurgist and crystallographer, including conducting some of the earliest investigations of fracture surfaces using scanning electron microscopy, and making significant contributions in the area of fracture mechanics. $^{20,21}$ The efforts of the two committees were closely aligned, sharing knowledge freely. Indeed, Tipper worked for periods of time in the Mechanics Division at the Naval Research Laboratory, invited by G.R. Irwin. While the efforts of Williams and Ellinger were seminal and encyclopedic, Tipper was able to fully unravel the story of brittle fracture. ${ }^{22}$ She developed systematic approaches to dealing with the data, and included careful analysis of both microstructure and composition, pulling together both her own data and the work of others in the field at the time. For example, she was able to show that, as opposed to simply looking at the $\mathrm{Mn}: \mathrm{C}$ ratio (viewed as important), it was also necessary to consider the microstructure. Considering only composition was insufficient. For example, a poor microstructure (coarse grains, stress concentrators) may overcome the expected benefits of a 'good' Mn:C heat, resulting in a plate that exhibits inferior notch sensitivity. In addition, she quantified preferential cleavage planes in the $\alpha$-ferrite (see Fig. 4), allowing for a simultaneous understanding of the roles of both fracture mechanics and crystal structure on this problem. Without a doubt, the rapid collection of large quantities of information by the U.S. and British governments, and the careful and methodological investigations by many, including Tipper, 


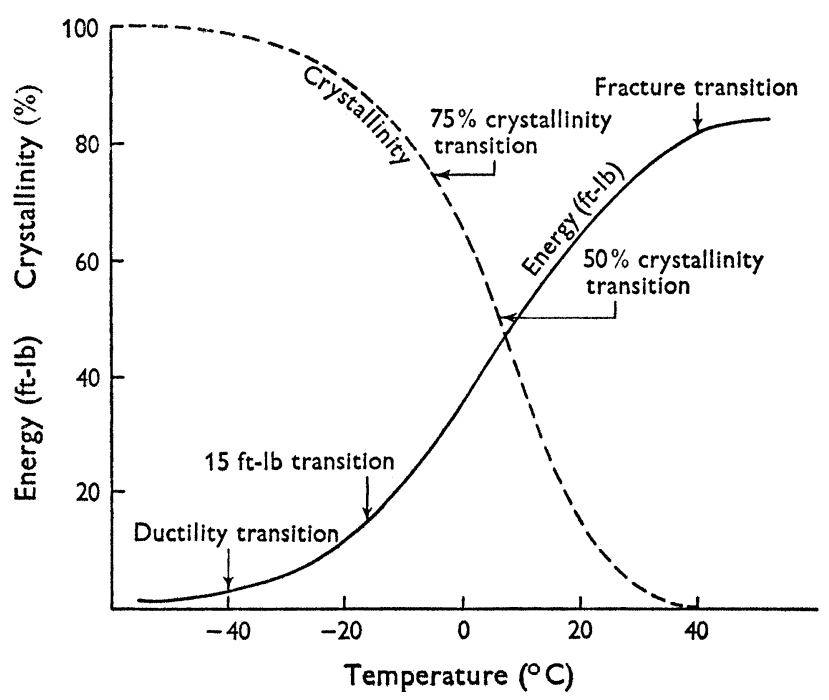

Fig. 4. Strategy proposed by Dr. C. Tipper to first understand mechanisms of the DBTT involving careful measurements of the "\% Crystallinity", which would correlate with brittle cleavage as opposed to ductile fracture. ${ }^{22}$

enabled the complex problem of notch-sensitive materials to be significantly understood in a very short period of time.

\section{The Remaining Metallurgical Background}

In the early $1950 \mathrm{~s}$, techniques for measuring notch sensitivity matured, especially for welded ship applications. Ship building had moved from riveted to welded structures, yet, as noted above, there were certain 'triggers' from welds (e.g., a preexisting geometric crack, and defects). ${ }^{23}$ In addition, weld processing introduced a new material with its own DBTT, as well as modifying (e.g., coarsening) the grain structures and the microstructure. Each alteration potentially led to susceptibility to this newly found phenomenon. The U.S. Navy needed to develop a better method to test welded structures and guarantee fracture-safe welded plates. Leveraging the knowledge gained in large part to the materials failures associated with many ships in World War II (including the Liberty Ships), the drop-weight test was developed to determine the transition temperature for welded steel. In order to mimic welding conditions in the steel, a small crackstarter bead is welded to the sample with a notch or crack in the center of the bead. The sample is then heated or cooled to a specific testing temperature. During the test, a guided free-falling weight impacts the bead on the sample. The sample is considered broken when the weld bead cracks, and the cracking reaches the sample surface. ${ }^{24}$ After a sample breaks, the testing temperature is increased by $5.6^{\circ} \mathrm{C}$, and the test is repeated until two consecutive samples do not break. For the drop-weight test, the lowest temperature at which two samples do not break is referred to as the NDTT. Following the Williams and Ellinger report and adopting this new method, the metallurgy division of the Naval Research Laboratory used the drop-weight test and found a NDTT of approximately $10^{\circ} \mathrm{C}$ for a WWII plate sample available from previous studies. This specific ship, a T-2 tanker, broke in two off the coast of Boston, Massachusetts, while the air temperature was $\sim 1.5^{\circ} \mathrm{C}$, well below the discovered NDTT. ${ }^{25}$ Importantly, this occurrence confirmed that the material was the source of failure, and not welding by alleged untrained workers.

The Bethlehem Steel Plant produced over 1 million tons of steel for ships assembled at the Bethlehem-Fairfield shipyard in Baltimore. ${ }^{26}$ Most, if not all, of that steel was produced using the openhearth process. ${ }^{27}$ At that time, this process was the most effective method of producing good quality steel. Improved quality control was identified as a national need due to irregularities found in steel during the expansion of the railways. ${ }^{28}$ As a result, organizations such as the American Society for Testing and Materials (ASTM) were founded to establish quality control standards through prescribed testing procedures. Prior to the Liberty ships, World War I provided an unprecedented challenge for the commercial steel industry to transform, producing the steel needed for tanks and ships. During this time, an extensive standardsmaking process came about due to this demand, which provided the framework for the revitalized steel production necessary for World War II. The standards successfully maintained the overarching goal for quality control throughout the war. Further, examining grades within a specified standard gives a thorough understanding of the material at hand. As noted previously, the standards that were in place were for static tensile properties, such as yield strength, ultimate tensile strength, and elongation to failure. The Liberty ships and other vessels clearly identified the need to consider additional properties, such as notch sensitivity, DBTT, and NDTT. Over the next decades, technologies evolved (i.e., the basic oxygen furnace) and practices changed. The standards responded soon after abandoning the open-hearth process altogether, allowing structural steel to be made from only basic oxygen or electric-arc processes. ${ }^{29}$

\section{The Liberty Ship Rivets}

While many will first recall that the majority of the Liberty ships used welding to join most of the structure (except for those, including the "John W. Brown", built at the Bethlehem-Fairfield shipyard in Baltimore), rivets were used in the ship structure and played key roles in the solution to the brittle cracking problems. ${ }^{2}$ In fact, it was a riveting strategy that was adopted which allowed these ships to continue to operate with a remarkable record of success even before the metallurgy of the problem was fully understood. Riveted seams were installed 
on the Liberty ships to act as crack arrestors. According to Capt. Walter Jaffee, ${ }^{2}$ during the restoration of the "John W. Brown", 15,000 rivets (mainly from the underwater portions of the hull) were replaced.

The Liberty ship rivets which are the subject of this study not only speak to this history but provide an opportunity to look at contemporary analogues to the plate material which is largely unavailable for modern studies. By combining the interpretations of the previous studies detailed above with modern metallographic analysis, it is possible to draw connections between the microstructure and performance of the plate steel used in Liberty ships, and how processing improvements have resulted in superior grades of steel. Further, it is possible to understand the role of the design of the joints in their failures. The technical details which follow focus on the metallurgy of two rivets: one original to the Liberty ship SS "John W. Brown", and an unused, modern replacement rivet.

\section{EXPERIMENTAL METHODS}

The two rivets, a 1942 original extracted from the Liberty ship SS "John W. Brown" during its restoration and an unused modern replacement were designated as the Original Rivet (OR) and New Rivet (NR) samples. Both samples were sectioned for grinding. For all polishing steps, an isopropyl alcohol solution was used as a lubricant/cleaning solution to mitigate corrosion. Coarse polishing began with 80 -grit wet/dry silicon carbide abrasive paper and progressed to an 800-grit step. Subsequently, the samples were subjected to fine polishing using a series of felt-pads and diamondsuspension grits, starting with $9-\mu \mathrm{m}$ diamond-suspension and ending with a $0.05-\mu \mathrm{m}$ suspension. Between polishing steps, the material was cleaned in an ultra-sonic bath with isopropyl alcohol. Following specimen preparation, the material was analyzed using a variety of techniques to characterize the composition and microstructure. Luvak laboratories analyzed the chemical composition of both rivets using combustion infrared detection and direct current plasma emission spectroscopy (DCPES). In addition, energy dispersive spectroscopy (EDS) was used to determine the composition of specific microstructural features when the specimens were being analyzed in the scanning electron microscope (SEM). An FEI Quanta SEM was also used to image the specimen microstructure. The results are presented below.

\section{RESULTS AND DISCUSSION}

\section{Composition}

Based on the available literature, original Liberty ship rivets did not have a specified composition. Generally, low carbon steels were chosen to satisfy a given mechanical property. This is not to say that the role of composition on some properties was not understood, rather that the variability in suppliers of the steel needed for this tremendous National effort, as well as the location-to-location compositional variability in heat, made the mechanical specification a more appropriate standard at the time. Given that the specified grade of rivets could not be directly determined from technical reports, the modern standards of similar parts are given. The standard for carbon structural steel is ASTM A36 (introduced in 1960) and would correspond to the plate material used in the hulls of the Liberty ships, while modern steel rivets are subject to the standard A502 (grade 1). Portions of these chemical standards are given in Table I. It should be noted that the compositions recorded from the Williams and Ellinger report are average values across many steel plates originating from different ships, different plate sources, and different thicknesses. Thus, it is not surprising that the compositions of Liberty ship plates varied wildly. Consequently, the standard deviations are not reported and provide little interpretable information.

Comparing the composition of the original rivet with the average compositions of the plates studied by Williams and Ellinger shows minor differences. The carbon content of the original rivet lies outside the scatter of measurements (0.17-0.37) made on recovered plates by Williams and Ellinger, but not significantly. The carbon content may appear to be slightly lower due to differences in the analytical techniques over the past 70 years, or may be slightly lower to decrease the flow stress during the upsetting of the rivet during ship-building. Further, every other element lies within the measurements made by Williams and Ellinger. Thus, it is reasonable to conclude that the original rivet and plate are likely of approximately the same grade of steel and made by the same process (the open-hearth furnace). Consequently, these rivets provide a steel analogue to the original plate, as that steel is largely not available for modern studies.

The Mn:C ratio is presented in Table I. Williams and Ellinger observed that the ratio of these two elements has a strong correlation with the notch sensitivity of the steels. This is not surprising as increasing carbon content decreases the energy required to fracture in a v-notch Charpy test and increases the DBTT. ${ }^{14,22}$ Conversely, Mn has the opposite effect. ${ }^{14,22}$ However, Williams and Ellinger also noted that the ratio, taken by itself, would have been an insufficient metric to fully understand the problem. Based upon the Williams and Ellinger report, the composition of the rivets corresponds to a $20.3 \mathrm{~J}$ impact threshold temperature of $\sim 5^{\circ} \mathrm{C}$ to $20^{\circ} \mathrm{C}$. Thus, the rivets would have exhibited the same brittle failure as the plates in the temperature conditions experienced by the Liberty ships. This underscores the fact that the 
Table I. Comparison of the Liberty ship deck materials, original rivets, and modern replacement rivet, with reference to modern standards of steel grades

\begin{tabular}{|c|c|c|c|c|c|c|}
\hline & $\begin{array}{c}\text { A502 (Grade 1) } \\
(\text { wt.\%) }\end{array}$ & $\begin{array}{c}\text { A36 } \\
(\mathbf{w t . \%})\end{array}$ & $\begin{array}{c}\text { Plate } \\
(\text { wt.\% })^{14}\end{array}$ & $\begin{array}{c}\text { Original rivet } \\
(\text { wt.\%) }\end{array}$ & $\begin{array}{c}\text { New rivet } \\
(\text { wt.\%) }\end{array}$ & $\begin{array}{l}\text { OR versus } \\
\text { NR } \% \text { diff. }\end{array}$ \\
\hline $\mathrm{C}$ & $0.11-0.27$ & 0.29 & 0.25 & 0.160 & 0.154 & -4 \\
\hline $\mathrm{Mn}$ & $0.27-0.93$ & $0.80-1.2$ & 0.42 & 0.480 & 0.660 & +38 \\
\hline $\mathrm{P}$ & $<0.07$ & $<0.04$ & 0.015 & 0.008 & 0.013 & +63 \\
\hline $\mathrm{S}$ & $<0.058$ & $<0.05$ & 0.033 & 0.042 & 0.029 & -31 \\
\hline $\mathrm{Si}$ & $\ldots$ & $0.15-0.4$ & 0.035 & 0.040 & 0.190 & +375 \\
\hline $\mathrm{Ni}$ & $\ldots$ & $\ldots$ & 0.044 & 0.057 & 0.093 & +63 \\
\hline $\mathrm{Cr}$ & $\ldots$ & $\ldots$ & 0.036 & 0.046 & 0.093 & +102 \\
\hline Mn:S ratio & $>4.66$ & $>16$ & $\sim 12.7$ & 11.43 & 22.76 & +100 \\
\hline $\mathrm{Mn}: \mathrm{C}$ ratio & $>1.0$ & $>2.75$ & $\sim 1.68^{\dagger}$ & 3.0 & 4.28 & \\
\hline
\end{tabular}

$\dagger$ The reported Mn:C ratio is given here as a ratio of the average values. Williams and Ellinger took the Mn:C ratio for every sheet, and then calculated the average of the ratio, which is 1.74 . Significant differences in OR versus NR are shown in bold

benefits of the rivets lay in the design of the joint. The welded structure allowed the cracks to propagate, whereas a riveted structure prevented crack propagation.

The differences in the composition of the original and modern rivets are also illuminating. While both rivets are within the allowables of A502 (grade 1), they vary significantly in their compositions. For example, the new rivet contains nearly five times more silicon, and has significantly increased $\mathrm{Mn}: \mathrm{C}$ and $\mathrm{Mn}: \mathrm{S}$ ratios. From a strict assessment of chemistry only, it would be difficult to conclude which rivet exhibited a better DBTT, as Si and Mn exhibit opposite effects. It is necessary to understand the microstructure of these steels to better understand the likely effect of the individual elements. What follows is an assessment of the presence of inclusions which is presented relative to chemical composition, and can impact the performance through interstitial solute gettering. Additional details, such as the partitioning of S, P, and C in the $\alpha$-ferrite, which is known to play a role in notch sensitivity, was not conducted as part of this study.

\section{Microstructure}

The microstructure of both rivets (the available analogue to the plate) consisted primarily of $\alpha$-ferrite and various types of inclusions. The size of an $\alpha$-ferrite region was determined ${ }^{30}$ to be roughly equivalent $(\mathrm{OR}=21 \mu \mathrm{m}, \mathrm{NR}=25 \mu \mathrm{m})$, indicating that the grain size would exhibit a negligible difference in the properties of these two rivets. ${ }^{22}$ The bulk of this microstructural analysis focuses on the observed inclusions, which are markedly different when comparing the original and modern rivets. These differences can be directly related to the improvements in steel processing that occurred in the decades following the Liberty ships. Inclusions found in steels can be one of five types: sulfides, oxides, silicates, nitrides, and phosphides. ${ }^{31}$ The first three (i.e., sulfides, oxides, and silicates) were observed in both the original and modern rivets, though in different distributions and compositions. Importantly, such analysis was not feasible in the previous seminal works by either Williams and Ellinger or Tipper. While inclusions were noted (especially by Tipper), the precise compositional nature of the inclusions were not.

\section{Sulfides}

The majority of the inclusions that were observed in the original rivet were manganese sulfide inclusions, the most common inclusion found in steel ${ }^{32}$ It is well known that the presence of these inclusions aids in overcoming the negative effects of iron oxides and iron sulfides ${ }^{27}$ which decreases ductility and reduces strength, respectively. The addition of manganese to liquid steel results in the precipitation of manganese oxide and manganese sulfide which are more thermodynamically stable than iron oxide and iron sulfide. Further, these manganese inclusions are relatively harmless and do not weaken the material. Often, the manganese-to-sulfur ratio is calculated when studying these inclusions. A higher $\mathrm{Mn}: \mathrm{S}$ ratio is preferred because this would reduce or eliminate any iron sulfide particles. The modern rivet has a higher $\mathrm{Mn}: \mathrm{S}$ ratio (22.76) compared to both the original rivet (11.43) and the plate (12.7), indicating a reduction in iron sulfide and, consequently, a higher strength.

Manganese sulfide inclusions can be categorized by their morphology, which is related to the concentration of aluminum in the steel. Type I MnS inclusions are equiaxed (i.e., globular) and are typically found in steels with high oxygen content and very low aluminum content. Type II MnS inclusions are better described as films or envelopes, and are in steels (or regions in segregated steels) that contain small amounts of aluminum. Type III MnS 

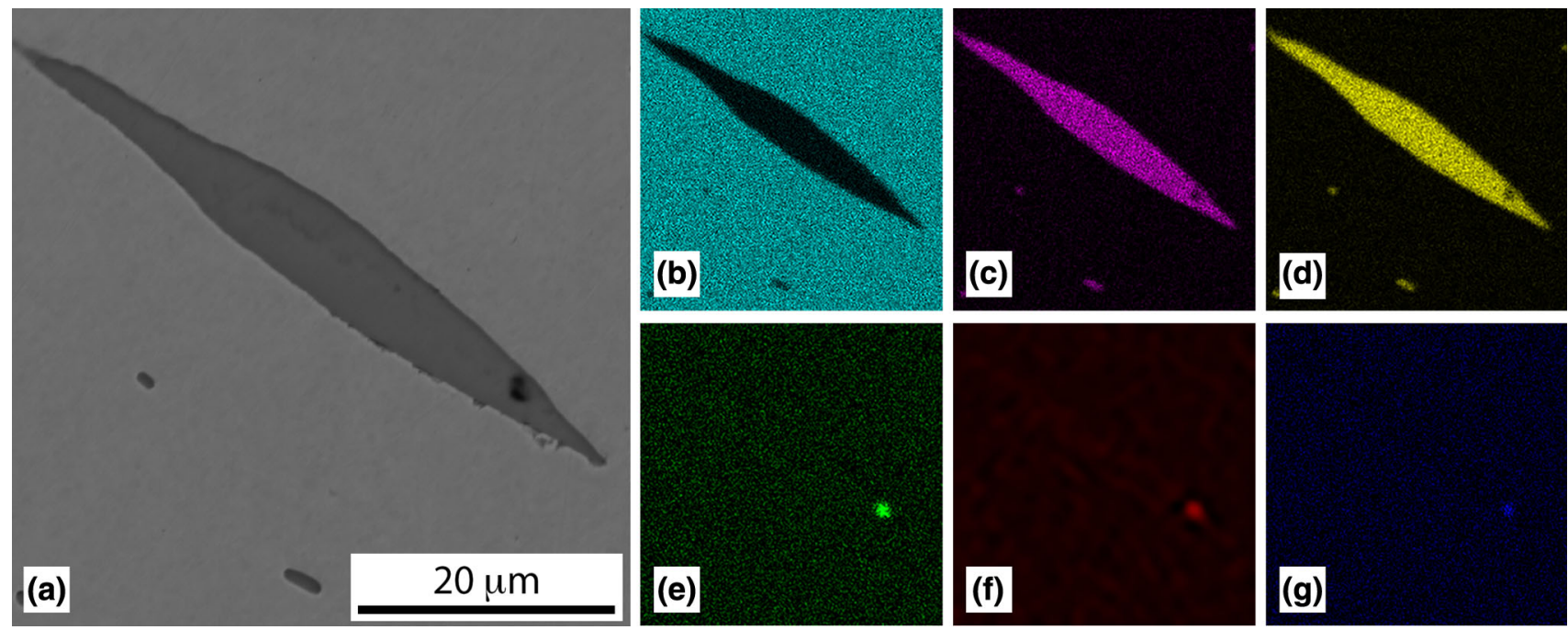

Fig. 5. Manganese sulfide inclusion with a nucleation site. (a) Back-scattered electron, (b) Fe, (c) Mn, (d) S, (e) Al, (f) O, (g) Si.

inclusions appear as faceted octahedral precipitates and are found in steels with an excess amount of aluminum.32 The MnS inclusions in both rivets are predominately type I, which begin as equiaxed structures and become elongated due to forming operations. These $\mathrm{MnS}$ inclusions are soft and deformable at low temperatures. ${ }^{33}$ The backscattered scanning electron micrograph presented in Fig. 5a and the corresponding EDS maps shown in Fig. 5b-g show one of the type I MnS precipitates in the original rivet. The inclusion appears to have nucleated from a smaller oxide inclusion containing aluminum, silicon, manganese, and oxygen according to EDS mapping (see Fig. 5e-g).

\section{Oxides}

While potentially having adverse effects on the mechanical properties, ${ }^{27}$ the presence of oxides represents an engineering tradeoff. Free oxygen can react with carbon to form $\mathrm{CO}$ and $\mathrm{CO}_{2}$ during processing, resulting in gas porosity and/or a reduced carbon content in the steel. Thus, selected elements are added to the steel to form thermodynamically stable oxides. ${ }^{34}$ Aluminum is a primary deoxidizer while silicon and manganese play lesser roles.

The volume fraction, size, distribution, composition, and morphology of the inclusions are the most significant factors which affect the mechanical properties $^{35}$ of the steel. These microstructural features are influenced by processing and the attending thermodynamic reactions. ${ }^{27}$ For example, longer ladle holding times result in the formation of more inclusions, and these inclusions float to the top due to their lower densities and lead to higher volume fractions of inclusions in the upper regions of the deoxidized ingots. ${ }^{32}$ Generally, if the steel is processed poorly, oxide inclusions can become brittle stress concentrators, and are detrimental to the mechanical properties. ${ }^{35}$ Further, the scale of the oxide inclusions will be related to the scale of any plasticity-induced discontinuity (i.e., delamination, particle cracking). The larger the particle, the poorer the ductility and toughness. The scale of the oxide inclusion has a very small influence on the DBTT itself, but does have an effect on the upper shelf energy. ${ }^{36}$

\section{Silicates}

As noted above, silicon can act as a deoxidizer, and can react not only with oxygen but also with other deoxidizing elements (including $\mathrm{Mn}$ ) to form more complex silicate inclusions. The presence of these inclusions makes the material easier to cast, although they may also coarsen the grains. As noted previously, the grain size of both steels are approximately equivalent. Specific processing conditions have reportedly led to manganese oxides reducing silicon, forming manganese silicates, ${ }^{32}$ as appears to be the case in Fig. 6 .

SEM imaging combined with EDS spot scans and EDS mapping revealed several varieties of oxide inclusions. Both rivets showed randomly distributed aluminum oxide inclusions throughout the material. Both rivets also exhibit sulfide formation regardless of oxide nucleation sites. Lastly, both rivets had spherical oxides that indicate a high oxygen activity. However, as noted above, there was an observable increase in the prevalence of manganese aluminum silicate inclusions in the new rivet. These manganese aluminum silicates were smaller, and are known to be more deformable than other oxide inclusions. ${ }^{33}$ For the sake of completeness, it is noted that x-ray diffraction (XRD) was also conducted, but there were no significant oxide peaks to determine the volume fraction of the inclusions. 

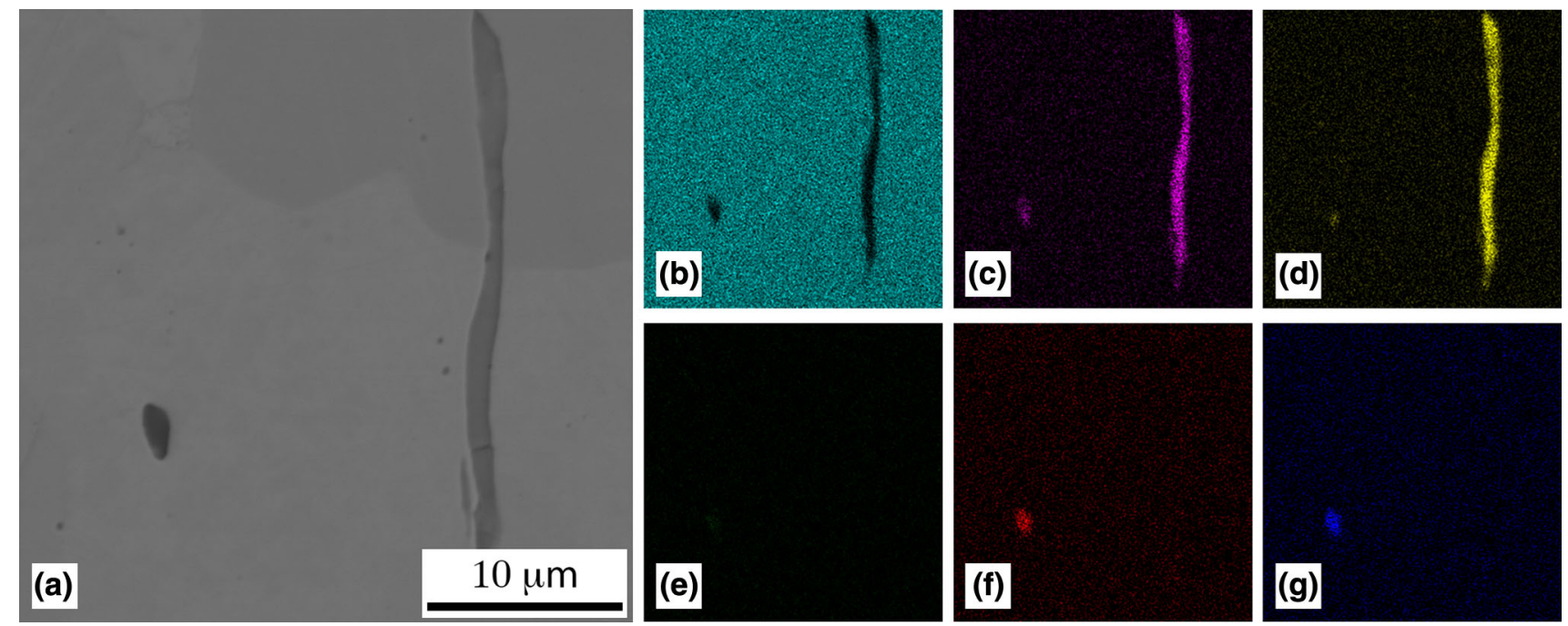

Fig. 6. Silicate and sulfide inclusion in the new rivet. (a) Back-scattered electron, (b) Fe, (c) Mn, (d) S, (e) Al, (f) O, (g) Si.
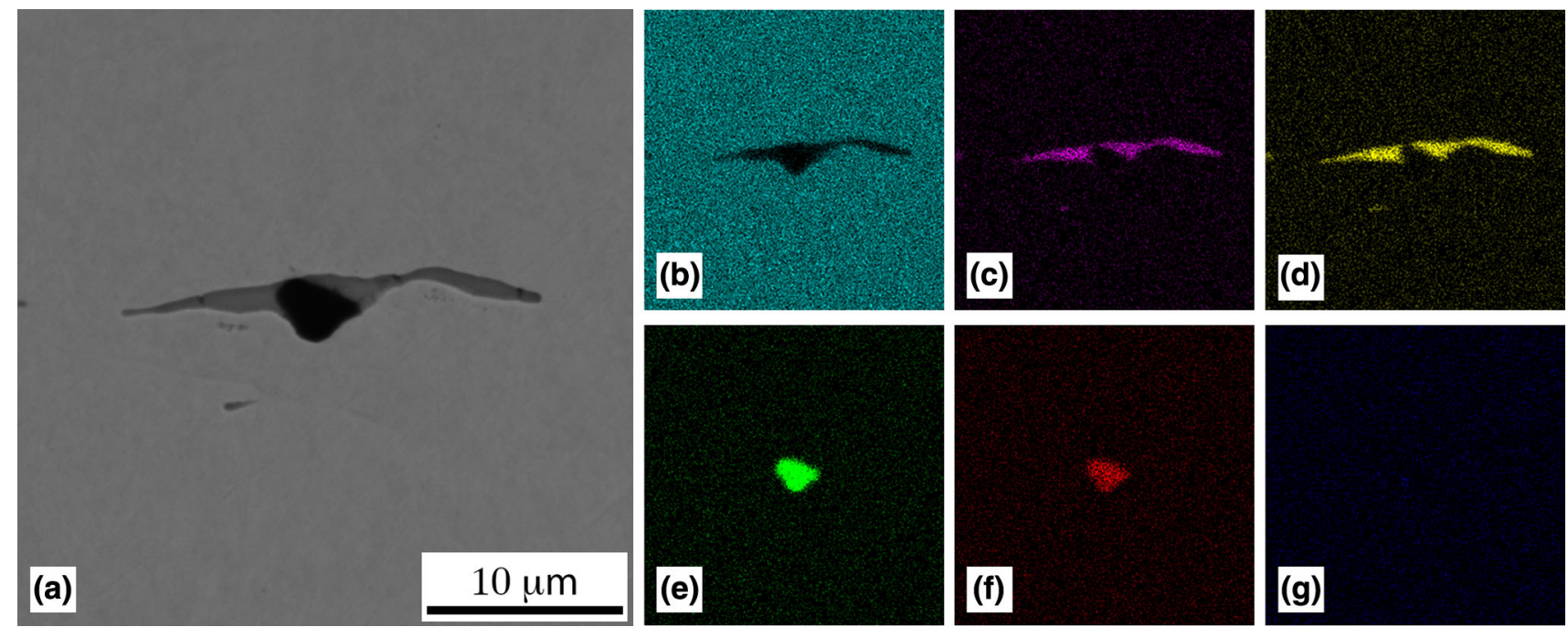

Fig. 7. Aluminum oxide inclusion acting as a nucleation site for $\mathrm{MnS}$ in the old rivet. (a) Back-scattered electron, (b) Fe, (c) Mn, (d) S, (e) Al, (f) O, (g) Si.

\section{Effect on DBTT}

Without question, the composition of steel affects the DBTT. The composition of the steel in the original rivet closely approximates the steel in the plate, and thus likely would have suffered similarly. Thus, the difference in design, that is, the difference between a monolithic welded structure compared to a riveted structure, is clear. The inferior DBTT of the steel was exposed by the welded structures, but not created by the welded structures. In addition, as pointed out by Dr. Tipper, the composition is an insufficient metric to understand the phenomenon. For example, the same elements that form inclusions (i.e., manganese and silicon) affect the DBTT, but more strongly affect the DBTT when in solution and less strongly when in inclusions. When $1 \mathrm{wt} . \%$ of manganese is added, the $20.3 \mathrm{~J}$ transition temperature is found to decrease by $55.6^{\circ} \mathrm{C}$, and when $1 \mathrm{wt} . \%$ of silicon is added, the transition temperature increases by $69.4^{\circ} \mathrm{C}$. According to the compositions measured in this work, considering only manganese, the new rivet would have a lower DBTT. However, considering only silicon, theoretically the original rivet would have a lower DBTT. ${ }^{37}$ However, as is also clear from the characterization conducted here, the increased silicon content (and the advances in steel making) have a profound impact on the inclusions present in the microstructure., as similar compositions can exhibit different microstructures and inclusions.

Specifically, the aluminum oxide inclusions are readily observed in the original rivet (see Figs. 5 and 7). Most of the oxides in the original material 
were spherical/equiaxed aluminum oxides observed to be in intimate contact with the $\mathrm{MnS}$ particles, most likely having served as initiation sites. The $\mathrm{Al}_{2} \mathrm{O}_{3}$ particles in the original material are fairly coarse $(\sim 5 \mu \mathrm{m})$, and coarser than the silicides and $\mathrm{SiO}_{2}-\mathrm{MnO}$ particles that are observed in the modern rivet ( 1-2 $\mu \mathrm{m}$; see Fig. 6 ). All oxides observed in the modern rivet contained some level of silicon. Further, no oxide was associated with the MnS particles in the modern rivets. The $\mathrm{SiO}_{2}-\mathrm{MnO}$ particles were more elongated and aligned to the rolling direction.

These subtle differences are important, and will impact the expected properties of the two materials as both plate analogues and as rivets. With respect to the mechanical properties, the $\mathrm{Al}_{2} \mathrm{O}_{3}$ particles are generally not deformable at any temperature. Thus, their direct contact with the MnS particles would likely reduce the upper shelf energy and possibly promote internal cracks in the as-received materials. This is due to the large differences in the plasticity of the $\mathrm{MnS}$ and $\mathrm{Al}_{2} \mathrm{O}_{3}$ particles. Further, the $\mathrm{SiO}_{2}-\mathrm{MnO}$ particles of the modern rivet are more deformable than the $\mathrm{Al}_{2} \mathrm{O}_{3}{ }^{33}$

Thus, everything else being equal, the larger and less deformable oxides in the original material in intimate contact with the MnS would have resulted in poorer properties (lower toughness, lower shelf energy) than the smaller and more deformable oxides which are somewhat removed from the $\mathrm{MnS}$ in the modern material. From the perspective of thermodynamics, the morphology of the aluminum oxides is directly related to the relative activities of oxygen and aluminum. When the activity of oxygen is high, the aluminum oxide inclusions tend to form spheres. Conversely, when the activities of aluminum and oxygen are equivalent and at intermediate levels, the inclusions tend to form more elongated dendritic-like structures. It is therefore possible to conclude that the activity of the oxygen was much higher for the original rivets, and that they had more time to coarsen during the processing.

\section{CONCLUSION}

This research has presented an opportunity to reflect upon the Liberty ships, the pivotal role they played in U.S. history, and the significant impact that they had on the understanding of physical metallurgy. Without the large number of vessels and the significant investment of critical reviews and intellectual capital to the problem by two governments, the ductile-to-brittle transition might have remained ignored or poorly understood. Individuals on both sides of the Atlantic played significant (and synergistic) roles in understanding the problem, especially Dr. Constance Tipper. However, while these vessels played important roles, much of the story has been forgotten.
The problem of hull cracks was a complex problem associated with the steel, naturally occurring weld defects, and the absence of seams where the cracks could arrest. They were not the result of inferior welders (e.g., Wendy the Welder), as was originally suggested. The solution to the cracking was to incorporate riveted structures. The steel of the rivet studied here is a reasonable analogue to the plate material, and would have suffered similarly poor properties. Yet, the design of riveted structures, even with the rivets that were used to "fix" the Liberty ships, was more accommodating of the inferior steel. It is evident from a comparison between the two rivets that the size, chemistry, and distribution of the precipitates is profoundly different. Specifically, in the original rivet-and by extension the original sheet-the adjoining $\mathrm{Al}_{2} \mathrm{O}_{3}$ / $\mathrm{MnS}$ inclusion clusters resulted in an undeformable particle immediately adjacent to a deformable particle, a characteristic which would have invariably resulted in microcracks due to the mismatch in plastic strain accommodation. Conversely, the modern steel contains more deformable oxides which are disassociated from the MnS particles, and consequently behave more as dispersions for strengthening. The composition of the modern grade reflects the knowledge gained following the discovery of the DBTT, in that the Mn content has been increased to improve the DBTT, while the increase in Si has been shown to result in the formation of more complex oxides and silicates as the result of the deoxidation steps in the steel making process.

\section{ACKNOWLEDGEMENTS}

This article would not have been possible without the significant efforts of a great many people to whom the authors are indebted. The authors are grateful to David A. Brice, Randa Franzen, and Sheena Grace Valentin for their supporting activities. The authors are immensely grateful to many individuals at the National Institute of Standards and Testing, including Jim A. Warren, Tim Foecke, Bill Luecke, and Keith Martin. PCC is grateful to Mike Kaufman of the Colorado School of Mines for helping to confirm the probable relationship between Ellis Reed-Hill and Robert E. Reed-Hill. PCC is also grateful to the University of North Texas, their Center for Advanced Research and Testing, as well as Iowa State University for their support. Lastly, acknowledgements must be made to the many volunteers whose efforts have preserved two of these ships, and consequently made this study possible.

\section{OPEN ACCESS}

This article is distributed under the terms of the Creative Commons Attribution 4.0 International License (http://creativecommons.org/licenses/by/4.0/), which permits unrestricted use, distribution, and reproduction in any medium, provided you give appropriate credit to the original author(s) and the 
source, provide a link to the Creative Commons license, and indicate if changes were made.

\section{REFERENCES}

1. Peter Elphick, Liberty: The Ships That Won the War, 1st ed. (Annapolis, MD: Naval Institute Press, 2001).

2. W.W. Jaffee, The Liberty Ships: From A to $Z$, 1st ed. (El Cerrito, CA: The Glenncannon Press, 2004).

3. E.F. Imhoff, Good Shipmates: The Restoration of the Liberty Ship John W. Brown, 1942-1946 (El Cerrito, CA: The Glenncannon Press, 2007).

4. B.J. Wulff, H. Imhoff and E.F. Imhoff, A Beautiful Ship (Baltimore, MD: Project Liberty Ship, Inc., 2009), DVD.

5. F.C. Lane, B.D. Coll, G.J. Fischer, and D.B. Tyler, Ships for Victory: A History of Shipbuilding Under the U.S. Maritime Commision, 1st ed. (Baltimore, MD: Johns Hopkins University Press, 1951).

6. S. Cooper, Liberty Ship: The Voyages of the John W. Brown, 1942-1946. (Annapolis, MD: Naval Institute Press, 1997.)

7. The National Park Service 'Park Net' contributors. Determining the Facts: Reading 1: The Liberty Ships, http://www. nps.gov/NR/twhp/wwwlps/lessons/116liberty_victory_ships/ 116facts1.htm. (Accessed 9 September 2015.)

8. Wikipedia Contributors, "Liberty ship" (Wikipedia, The Free Encyclopedia), https://en.wikipedia.org/w/index.php?title=Lib erty_ship\&oldid=677344810. (Accessed 9 September 2015.)

9. Wikipedia Contributors, Rosie the Riveter/World War II Home Front National Historical Park (Wikipedia, The Free Encyclopedia), https://en.wikipedia.org/w/index.php?title= Rosie_the_Riveter/World_War_II_Home_Front_National_ Historical_Park\&oldid=648276626. (Accessed September $\overline{9}$ 2015.)

10. Wikipedia Contributors, Rosie the Riveter (Wikipedia, The Free Encyclopedia), https://en.wikipedia.org/w/index.php?ti tle=Rosie_the_Riveter\&oldid=680265636. (Accessed 9 September 2015.)

11. The U.S. Coast Guard Contributors, Eastwind, 1944, http:// www.uscg.mil/history/webcutters/img/Eastwind-Circles_Fort Mercer-19Feb52.jpg, last modified 11/17/2014. (Accessed 9 September 2015.)

12. Contributors, Why the RMS Titanic Fractured: Clues from the Ship's Hull (Basal Science Clarified), https://bsclarified. wordpress.com/2012/04/12/why-the-rms-titanic-fractured-cl ues-from-the-ships-hull/. (Accessed September 9, 2015.)

13. E.P. De Garmo, J.T. Black, and R.A. Kohser, DeGarmo's Materials and Processes in Manufacturing, 11th ed. (Hoboken, NJ: Wiley, 2011).

14. M.L. Williams, and G.A. Ellinger, "Progress Summary on Investigation of Fractured Steel Plates Removed From Welded Ships," Ship Structure Committee Report, National Bureau of Standards, Feb 25, 1949.

15. The Michigan Alumnus, vol. 51 (22 September 1945), p. 508.

16. Karen Kravcov Malcom, Ancestors of George Earle Burroughs, http://www.johncolemanburroughs.com/family/GeorgeEarle BurroughsAncestors.doc. (Accessed 9 September 2015.)

17. Military Times, Hall of Valor, Ellis Reed-Hill, http://valor. militarytimes.com/recipient.php?recipientid=308751. (Accessed 9 September 2015.)
18. Contributors, University of Florida Foundation, "Robert E. Reed-Hill Scholarship," https://www.uff.ufl.edu/Scholar ships/ScholarshipInfo.asp?ScholarshipFund=008389. (Accessed 9 September 2015.)

19. K. Zappas, "Constance Tipper Cracks the Case of the Liberty Ships," JOM, in this issue.

20. Contributors, University of Cambridge, "Constance Tipper", http://www-g.eng.cam.ac.uk/125/1925-1950/tipper.html. (Accessed September 9, 2015.)

21. Contributors, University of Cambridge, "Constance Tipper", http://www-g.eng.cam.ac.uk/125/1925-1950/tipper2.html. (Accessed September 9, 2015.)

22. C. Tipper, The Brittle Fracture Story Tipper, Constance Fligg Elam (Cambridge, England: University Press, 1962).

23. P.P. Puzak, E.W. Eschbacher, and W.S. Pellini, Weld. J. 31, 561 (1952).

24. J.M. Holt, and P.P. Puzak (eds), Drop-weight Test for Determination of Nil-ductility Transition Temperature, User's Experience with ASTM Method E 208, vol. 919 (West Conshohocken, PA: ASTM International, 1986).

25. P.P. Puzak, A.J. Babecki, and W.S. Pellini, Weld. J. Res. Suppl. 13, (1958).

26. E. John, "Maryland in the 1800-1900s, 'Liberty Ships and Bethlehem Steel", Dons Maryland History, a history archive designed and edited by students at Loyola Blakefield, Towson, Maryland. http://donsmarylandhistory.wikispaces. com/Liberty+Ships+and+Bethlehem+Steel+by+John+E. (Accessed 9 September 2015.)

27. J. Camp and C.B. Brancis, The Making, Shaping and Treating of Steel, 5th ed. (Pittsburgh, PA: Carnagie Illinois Steel Corporation, 1941), p. 347.

28. ASTM Contributors, 1898-1998-A Century of Progress, Chapter 2: Extending the Influence, http://www.astm.org/ HISTORY/hist_chapter2.html. (Accessed September 9, 2015.)

29. ASTM A6: Standard Specification for General Requirements for Rolled Structural Steel Bars, Plates, Shapes, and Sheet Piling (West Conshohocken, PA: ASTM International, 2014).

30. P. Collins, B. Welk, T. Searles, J. Tiley, J.C. Russ, and H.L. Fraser, Mater. Sci. Eng. A 508, 174 (2009).

31. D.H. Herring, "Steel Cleanliness: Inclusions in Steel, Industrial Heating-The Heat Treat Doctor" (August 2009), pp 18-20, http://www.IndustrialHeating.com.

32. R. Deckers, Non-metallic Inclusions in Liquid Steel (Ph.D. thesis, Katholieke Universiteit Leuven, Belgium, 2002), pp. $7-15$

33. Niclas Ånmark, Andrey Karasev, and Pär Göran Jönsson, Materials 8, 751 (2015).

34. J. Camp and C.B. Brancis, The Making, Shaping and Treatment of Steel, 7th ed. (Pittsburgh, PA: Carnagie Illinois Steel Corporation, 1957), p. 328.

35. L. Zhang and B.G. Thomas, Metall. Mater. Trans. B 37, 733 (2006).

36. S. Liu, Q. Huang, C. Li, and B. Huang, Fusion Eng. Des. 84, 1214 (2009).

37. J.M Kraft, and A.M. Sullivan, Report No. SSC-139 Final Rpt of Project SR-142, National Academy of Science-National Research Council (27 December 1961) 